\title{
Inhibitory Potential of Mangiferin on Glucansucrase Producing Streptococcus mutans Biofilm in Dental Plaque
}

\author{
Promise M. Emeka ${ }^{1, * \mathbb{D}}$, Lorina I. Badger-Emeka ${ }^{2}{ }^{(}$, Hairul-Islam M. Ibrahim $^{3}$, \\ Krishnaraj Thirugnanasambantham ${ }^{4}$ and Jamal Hussen ${ }^{5}$ (D) \\ 1 Department of Pharmaceutical Science, College of Clinical Pharmacy, King Faisal University, Al Ahsa 31982, \\ Saudi Arabia \\ 2 Department of Biomedical Science, College of Medicine King Faisal University, Al Ahsa 31982, Saudi Arabia; \\ lbadgeremeka@kfu.edu.sa \\ 3 Biological Science College of Science, King Faisal University, Al Ahsa 31982, Saudi Arabia; \\ himohamed@kfu.edu.sa \\ 4 Pondicherry Centre for Biological Science and Educational Trust, Kottakuppam 605104, Tamilnadu, India; \\ researchdirector@pcbsindia.com \\ 5 Department of Microbiology College of Veterinary Medicine, King Faisal University, Al Ahsa 31982, \\ Saudi Arabia; jhussen@kfu.edu.sa \\ * Correspondence: pemeka@kfu.edu.sa; Tel.: +966-503239033
}

Received: 31 October 2020; Accepted: 20 November 2020; Published: 23 November 2020

\begin{abstract}
Glucansucrase secreted by Streptococcus mutans and composed of virulence genes alters oral microbiota, creating adherent environment for structural bacteria colony forming dental biofilm. The present investigation studied the inhibitory and binding potentials of mangiferin against S. mutans and its enzyme glucansucrase implicated in biofilm formation. Antibacterial activity against planktonic S. mutans was carried out. Using reverse transcription PCR, the expression of crucial virulence genes, $g t f B, g t f C, g t f D, g b p B$, and comDE were determined. The effect of mangiferin on teeth surfaces biofilm was ascertained by scanning electron microscopy (SEM). Docking analysis of $S$. mutans glucansucrase and mangiferin revealed the binding energy of -7.35 and ten hydrogen interactions. Antibacterial study revealed that mangiferin was not lethal to planktonic S. mutans, but a concentration-dependent inhibition of glucansucrase activity was observed. The inhibitory effect of water-insoluble glucan synthesis was apparently more marked relative to water-soluble glucan synthesis attenuation. Mangiferin significantly downregulated the expression of the virulence genes, indicating a mechanism involving glucanotranferases, specifically inhibiting colony formation by attenuating bacterial adherence. SEM images revealed that $S$. mutans biofilm density was scanty in mangiferin treated teeth compared to non-treated control teeth. Our data therefore suggest that mangiferin inhibited S. mutans biofilms formation by attenuating glucansucrase activities without affecting bacteria growth.
\end{abstract}

Keywords: mangiferin; S. mutans; glucansucrase; dental plaque; biofilm

\section{Introduction}

Dental plaque is regarded as one of the most common biofilm-related infectious dental problems reported in public health settings [1]. Plaque formation can cause dental caries, periodontitis, and endodontic infections [2,3], with resultant infections leading to dental decay. The public health problem of dental plaques and disease of dental caries are known to cut across all strata of the entire human population [4]. This has been attributed to the consumption of dietary free sugars (sucrose), either as 
additives or preservatives, and they are linked to biofilm induced tooth decay $[5,6]$. The phenomenon of biofilm formation is complex with its control suggested to be a critical approach in curtailing the challenges faced by healthcare professionals [7]. Generally, dental plaques occur when the oral microbial $\mathrm{pH}$ is lowered, thereby creating the presence of increased acid producing and acid tolerant bacteria in a structurally and functionally organized biofilm formation [8]. Subsequently, as plague develops over time, the low $\mathrm{pH}$ becomes dominant and demineralizes the enamel and dentin [9]. The resultant plaque develops in such an ordered way that it is of a diverse microbial composition. As plague formation evolves over time, a low $\mathrm{pH}$ becomes dominant, demineralizing the enamel and dentin [9]. One of most common bacteria associated with dental plaques and a major contributor to the breaking down of tooth enamel, causing tooth decay, is Streptococcus mutans (S. mutans) [9]. The ability to cause dental plaque biofilm by this bacterium has been attributed to glucansucrase, an enzyme secreted extracellularly by $S$. mutans. Glucansucrase is reported to use fermentable carbohydrates to form high molecular-weight sticky glucan that is associated with the pathogenesis of biofilm production [10]. Extracellular glucan is a critical virulent element of $S$. mutans and can either be water soluble or insoluble contributing to the development of dental biofilm [11]. The main component of these virulent genes is three glucanotransferase enzymes $(g t f t B, g t f C, g t f D)$. They catalyze the synthesis of extracellular glucans in concert with fermentable carbohydrates, all of which are important as virulence factor in biofilm formation. Therefore, the pathogenicity of $S$. mutans is dependent on the virulence elements that enable it to adapt to low oral $\mathrm{pH}$ due to its characteristic aciduricity property [12]. The virulence characteristics such as mass, viscosity, and stickiness creating an adherent environment for the bacterium to survive and thrive on teeth surfaces, thus contributing to the stability of structural dental plaque integrity [10-12]. In addition to this, glucans possess binding proteins, an example of which is the glucan binding protein B $(G b p B)$ that facilitates the binding of bacteria to secreted glucans [13]. Furthermore, S. mutans produces two-component signal transduction system protein, ComDE [14], known to regulate the expression of virulent gene elements. As an environmental sensor, downregulation of this gene will result in biofilm defects [15]. Currently, the treatment of dental biofilm involves the mechanical removal of the plaque and the use of antimicrobial mouthwash such as chlorhexidine. However, these agents are non-specific in their action, and hence disrupt the oral microbiome by targeting commensals. Their reported side effects include teeth discoloration and gingival epithelial cells cytotoxicity $[16,17]$. In view of these treatment limitations, coupled with the emergence of bacterial resistance, alternative molecules of natural origin with potential antibacterial activity that have been used as remedies could be evaluated. A recent study reported a number of natural compounds, such as anthraquinones, apigenin, chitosan, $\alpha$-mangostin, and myricetin to exhibit anti-biofilm activities. According to the report, most of these products are not selective in their action [18]. Therefore, there is a need for alternative compounds with selective biofilm inhibitory potential targeting S. mutans without altering the oral microflora as well as having minimal side effects. One such compound is mangiferin, a major component of Mangifera indica, which belongs to the Anacardiaceae family, and has been documented to have a promising pharmacological profile $[19,20]$. Extracts of Mangifera indica have been used in herbal medicine for various indications [21,22]. Studies also reported an anti-adherence effect of the extracts of Mangifera indica on early and late plaque bacterial colonizers [23,24]. Periodontitis is caused by organisms, which colonize biofilm, therefore the action of S. mutans in attracting various bacteria strains such as Aggregatibacter actinomycetemcomitans, could induce inflammatory reactions [25]. Carvalho et al., [21], observed that orally administered mangiferin was effective in the treatment of experimental periodontitis in rats. In addition, the antimicrobial activity of mangiferin against $S$. mutans GS-5, a cariogenic strain, has been documented [26]. In addition, other compounds of natural origin, such as biacalm and palmtoylethanolamide, were found to be effective in the treatment of periodontitis [27]. Based on the previous studies that showed the effectiveness of mangiferin in the treatment of experimental periodontitis in rats and the inhibition of the activity of cariogenic strain S. mutans, we hereby further evaluate its antibiofilm potential. We hypothesize that it might be an effective natural agent against dental plaque development by inhibiting 
glucansucrase activity. Therefore, the present investigation evaluated the anti S. mutans activity of mangiferin and its inhibitory activity against glucansucrase using an enzymatic assay. Also, by using computational and biological assays, we investigated the antibacterial activity of mangiferin against planktonic S. mutans and its binding potential to glucansucrase. We also evaluated the inhibitory potential of mangiferin on glucansucrase activity and its ability to form biofilms. Furthermore, the impact of mangiferin on the expression of the virulence genes, namely $g t f B, g t f C, g t f D, g b p B$, and $\operatorname{com} D E$, was determined. This was undertaken with a view to ascertaining the anti $S$. mutans biofilm formation by mangiferin, a naturally available and less toxic substance than the current available pharmaceutical products. The null hypothesis to reject is that there is no significant difference between the mangiferin treated group and control group.

\section{Materials and Methods}

\subsection{Chemicals and Bacteria Strain}

Streptococcus mutans (S. mutans) MTCC 890 obtained lyophilized culture from the Institute of Microbial Technology (IMTECH), Chandigarh, India was used for the investigation. This was sub-cultured in Brain heart infusion (BHI) broth and incubated at $37^{\circ} \mathrm{C}$ for $24 \mathrm{~h}$. All the chemicals used in the study were bought from Himedia, India, unless otherwise stated.

\subsection{Preparation of Protein Structure, Ligand Structure and Active Site Prediction}

The RCSB database (http://www.rcsb.org/pdb/home/home.do) was used to retrieve the three-dimensional structure of $S$. mutans glucansucrase (3AIB). While the mangiferin ligand chemical structure was be retrieved from the compound database of Pubchem, (http://www.ncbi.nlm.nih.gov/ search). Ligand structures were retrieved in sdf was converted to pdb format with Pymol software (Schrodinger, LLC. 2010. The PyMOL Molecular Graphics System, Version 2.3.1). Also, using Computed Atlas of surface Topography of proteins (CASTp), the possible binding sites of Glucansucrase were ascertained to include pockets located on protein surfaces as well as voids buried in the protein interior.

\subsection{Molecular Docking}

Earlier described methods [28] for docking calculations were performed with AutoDock (version 1.5.2 revision 2) and executed with AutoDock version 4.2. The mangiferin that acted as the reference drug for procedure validation was docked in to the active site. In addition, the assignment of a perfect grid to each ligand and the subsequent obtaining of grid box values are as described previously [28]. Based on the binding energy, each resulting docked conformed ligand were ranked into cluster and visually analysed using the PyMOL software version 2.3.1.

\subsection{Anti-microbial Activity of Mangiferin and Time-Kill Assay}

A disc diffusion assay was used to evaluate the antibacterial effect of varying dilutions of mangiferin on cariogenic S. mutans. The following concentrations of mangiferin $125 \mu \mathrm{m}, 250 \mu \mathrm{m}, 500 \mu \mathrm{m}$ and $1000 \mu \mathrm{m}$ were used for the screening of its antimicrobial effect while DMSO and ciprofloxacin $(20 \mu \mathrm{g}))$ were the negative and positive controls respectively. The method described earlier [29] was used for the time kill assay of mangiferin against $S$. mutans. A bacterial suspension made up of $4 \times 10^{6} \mathrm{CFU} / \mathrm{mL}$ of $S$. mutans was prepared in tubes containing $8 \mathrm{mLs}$ of BHI broth to which mangiferin concentrations that ranged between $62.5-1000 \mu \mathrm{m}$ were added. A vehicle control was also set up and this consisted of DMSO and bacterial inoculum. All tubes were incubated at a temperature of $37^{\circ} \mathrm{C}$ in a shaking incubator for $42 \mathrm{~h}$. At time intervals of $0,24,30,36$, and $42 \mathrm{~h}, 1 \mathrm{~mL}$ of the bacterial suspension was drawn out, serially diluted in BHI broth, and then plated out on Muller Hilton agar. All plates were incubated for $24 \mathrm{~h}$ at a temperature of $37^{\circ} \mathrm{C}$, after which colony-forming units (CFU) were counted. 


\subsection{Biofilm Susceptibility Assay}

The $S$. mutans biofilm inhibitory potential of mangiferin was performed in a sterile 24 well cell culture plate was used to determine the inhibitory effects of mangiferin on $S$. mutans biofilm as had been previously described [30]. Tubes of bacterial suspension consisting of $1 \times 106 \mathrm{CFU} / \mathrm{mL}$ of S. mutans in BHI broth supplemented with $1 \%(\mathrm{wt} / \mathrm{vol})$ sucrose and varying mangiferin concentrations $(62.5-1000 \mu \mathrm{m})$ were incubated at $37^{\circ} \mathrm{C}$ for a $72 \mathrm{~h}$ period. Media with DMSO was employed as vehicle control. Media and mangiferin with respective concentrations were refilled with every $24 \mathrm{~h}$. At $72 \mathrm{~h}$ post incubation, the supernatant containing unbound cells and media components from each well was removed and stained with $0.1 \%(\mathrm{wt} / \mathrm{vol})$ crystal violet solution for $5 \mathrm{~min}$. Plates were then rocked in $95 \%$ ethanol at room temperature for $30 \mathrm{~min}$ and absorbance recorded at $595 \mathrm{~nm}$. In addition, S. mutans biofilms were cultured on glass coverslips with different concentrations of mangiferin $(0,62.5,125,250,500$, and $100 \mu \mathrm{m})$ for $24 \mathrm{~h}$ at $37^{\circ} \mathrm{C}$. The coverslips were washed trice with sterile Phosphate Buffered Saline (PBS) to remove unbound cells and stained for $30 \mathrm{~min}$ in the dark with Acridine orange. A fluorescent microscope (Optika, Germany) was used to record image stacks in five random locations at 40x magnification. In each experiment, the light intensity, background level, and contrast were maintained at the same level.

\subsection{The Assay of Glucansucrase Enzyme Inhibition}

The method used earlier by other researchers [31] was employed in the assay glucansucrase enzyme. To this effect, S. mutans was used as the source for the extraction of crude glucansucrase enzyme using the method previously described [31]. The bacterium was inoculated into $50 \mathrm{~mL}$ of an enzyme-producing medium made of BHI supplemented with $1 \%$ sucrose in a $250 \mathrm{~mL}$ flask. This was incubated under a 180 -rpm shaking condition at a temperature of $25^{\circ} \mathrm{C}$. To separate the cells, samples were drawn out, centrifuged at 10,000 rpm for $10 \mathrm{~min}$ at $4{ }^{\circ} \mathrm{C}$ and the cell-free supernatant used for enzyme assay. The method described by Kim et al. [32] was used for enzyme assay with the reaction mixture consisting of different mangiferin concentrations, $100 \mathrm{~mm}$ sucrose, $50 \mathrm{~mm}$ sodium acetate buffer ( $\mathrm{pH}$ 5.2), and $20 \mu \mathrm{L}$ cell free extract. The resultant was incubated for $30 \mathrm{~min}$ at a temperature of $30{ }^{\circ} \mathrm{C}$ while the end product of sucrose quantified dinitrosalicylic acid (DNS) method. Obtained results were calculated in enzymatic units with one unit defined as the amount of glucansucrase enzyme required to catalyse the release of $1 \mu \mathrm{m}$ fructose per min at $30^{\circ} \mathrm{C}$.

\subsection{Scanning Electron Microscopic Analysis}

The scanning electron microscope was used to examine the effect of mangiferin on tooth surfaces with S. mutans biofilm. Human upper premolar teeth obtained from the reserved bank of Teeth " $\mathrm{N}$ " Jaws Center, Chennai (India) was used for the analysis. They formed part of those obtained in patient care therefore needing no informed consent from the patients. An earlier described method [33] was used for the preparation and processing of tooth samples. A bacterial suspension consisting of $1 \times 109 \mathrm{CFU} / \mathrm{mL}$ S. mutans inoculated into $1 \mathrm{~mL}$ of $\mathrm{BHI}$ that was supplemented with $1 \%$ sucrose was introduced to a 24-well micro titre containing sterile teeth. To another set up containing, the same preparation was added $500 \mu \mathrm{m}$ of mangiferin. All set up were incubated for a period of $48 \mathrm{~h}$ at $37^{\circ} \mathrm{C}$. Obtained sample were fixed in $2.5 \%$ glutaraldehyde for one hour followed by dehydration in increasing concentrations $(25 \%, 50 \%, 75 \%, 95 \%)$ of ethanol for a period of $30 \mathrm{~min}$ each. Final dehydration was for $10 \mathrm{~min}$ in $100 \%$ ethanol before allowing too dry at room temperature for $4 \mathrm{~h}$. Samples coated with platinum/palladium were examined using JEOL JCM-6000 scanning electron microscope (JEOL, Ltd., Tokyo, Japan).

\subsection{Analysis of Bacterial Adhesion and Exopolysaccharide (EPS) Synthesis}

Viable CFU of $S$. mutans biofilm teeth samples that of untreated and mangiferin treated and their polysaccharide composition were analysed according to methods described previously [34]. 
In addition, water and insoluble EPS were extracted as previously described [35], while quantification was by colorimetric assays according to earlier described method [36].

\subsection{RNA Isolation, Reverse Transcription, and Quantitative Real-Time PCR}

RNA was extracted from S. mutans biofilms treated with 0,500 , and $1000 \mu \mathrm{m}$ mangiferin concentrations using TRIzol reagent (Sigma-Aldrich) according to manufacturer's guidelines. The extracted RNA served as the template for reverse transcription using the cDNA synthesis kit (Takara) according to the guidelines of the manufacturers. The resultant cDNA was stored at $-20{ }^{\circ} \mathrm{C}$ until needed for real-time PCR and served as the template for qPCR assay. The 16S rRNA primers used in the investigation are shown in Table 1. Quantitative PCR assay was performed using Qiagen (Hilden Germany) Rotor-Gen ${ }^{\circledR} \mathrm{Q}$ thermal cycling system. A $20 \mu \mathrm{L}$ of PCR reaction mixture was made up of $2 \mu \mathrm{L}$ of template cDNA, SYBRGreen PCR Master Mix (Thermo Scientific), and $0.5 \mu \mathrm{m}$ appropriate forward and reverse PCR primers each. The programming was as follows: initial incubation was carried out for $2 \mathrm{~min}$ at $50^{\circ} \mathrm{C}$ this was followed by 40 cycles of denaturation at $95^{\circ} \mathrm{C}$ for $15 \mathrm{~s}$, then annealing and extension at $60^{\circ} \mathrm{C}$ for $60 \mathrm{~s}$. The resultant cDNA and those of the negative control were amplified using the primers shown in Table 1 . The fold changes in gene expression were calculated with the $\Delta \Delta \mathrm{Ct}$ method and expressed according to recommendation [37].

Table 1. Nucleotide sequences of primers used for relative quantification of expression pattern of genes involved in S. mutans biofilm formation.

\begin{tabular}{|c|c|c|c|}
\hline Gene & Primer Sequence $\left(5^{\prime}-3^{\prime}\right)$ & $\begin{array}{l}\text { Amplicon } \\
\text { Size (bp) }\end{array}$ & Role in Biofilm Formation \\
\hline$g t f B$ & $\begin{array}{l}\text { FP: AGCAATGCAGCCAATCTACAAAT } \\
\text { RP: ACGAACTTTGCCGTTATTGTCA }\end{array}$ & 95 & $\begin{array}{l}\text { Water insoluble glucan } \\
\text { production. }\end{array}$ \\
\hline$g t f C$ & $\begin{array}{l}\text { FP: GTGCGCTACACCAATGACAGAG } \\
\text { RP: GCCTACTGGAACCCAAACACCTA }\end{array}$ & 107 & $\begin{array}{l}\text { Water soluble and insoluble } \\
\text { glucan production. }\end{array}$ \\
\hline$g t f D$ & $\begin{array}{c}\text { FP: TGGCACCGCAATATGTCTCTTC } \\
\text { RP: CAATCCGCAATAACCTGAATACCG }\end{array}$ & 183 & $\begin{array}{l}\text { Water soluble glucan } \\
\text { production. }\end{array}$ \\
\hline$g b p B$ & $\begin{array}{l}\text { FP: ATGGCGGTTATGGACACGTT } \\
\text { RP: TTTGGCCACCTTGAACACCT }\end{array}$ & 50 & Glucan binding protein. \\
\hline $\operatorname{comDE}$ & $\begin{array}{c}\text { FP: ACAATTCCTTGAGTTCCATCCAAG } \\
\text { RP: TGGTCTGCTGCCTGTTGC }\end{array}$ & 80 & $\begin{array}{l}\text { Competence-stimulating } \\
\text { peptide involved in quorum } \\
\text { sensing mechanism }\end{array}$ \\
\hline $16 S$ & $\begin{array}{c}\text { FP: CCTACGGGAGGCAGCAGTAG } \\
\text { RP: CAACAGAGCTTTACGATCCGAAA }\end{array}$ & 100 & \\
\hline
\end{tabular}

\subsection{Hemo Toxicity}

Freshly obtained EDTA human blood (A, Rh+) from blood bank of A. G. Padmavathi Hospital Blood Bank, Puducherry, India was washed three times by centrifugation ( $2500 \mathrm{rpm}$ for $10 \mathrm{~min}$ ) in PBS at room temperature $\left(20-25^{\circ} \mathrm{C}\right)$. Lymphocytes and platelets (Buffy coat) were removed from gradient centrifugation and a 10\% red blood cells (RBC) suspension was prepared in PBS (1×), aliquots of $2.5 \mathrm{~mL}$ of $10 \%$ RBC was mixed with 250 and $500 \mu \mathrm{m}$ of mangiferin. Chlorhexidine $0.2 \%$ was used as positive control. Glutaraldehyde was added to stop the reaction. The supernatant was removed and the liberated hemoglobin in the supernatant was measured spectrophotometrically as absorbance at $541 \mathrm{~nm}$. For negative control 5\% DMSO with 10\% of RBC suspension making a final concentration of $1 \%$ was used. The experiment was performed in triplicate and mean \pm standard deviation (SD) was calculated as follows: $\%$ Hemolysis $=($ Absorbance sample/Absorbance positive control $) \times 100$. 


\subsection{Oral Cell Toxicity}

The biocompatibility of mangiferin in human oral epithelial cell line (HOEC) was procured from the Division of Cellular Immunology, Pondicherry Centre for Biological Sciences, India. The cells were routinely maintained in culture flasks (TPP, Switzerland), at $37^{\circ} \mathrm{C}$ in $5 \% \mathrm{CO}_{2}$, in complete DMEM media (Gibco, MA).

MTT Assay and Cytotoxicity Analysis

Determination of cytotoxic activity of mangiferin, $80 \%$ confluent cell lines were trysinized and seeded on 96-well plates at a density of $5 \times 10^{3}$ cells per well. The cells were incubated overnight and treated with concentrations of 250 and $500 \mu \mathrm{m}$ mangiferin, while $0.2 \%$ Chlorhexidine was used as positive control. Negative control group cells were treated with $5 \% \mathrm{DMSO}$ at the same concentration with culture media and attain final concentration of $1 \%$ DMSO $(\mathrm{v} / \mathrm{v})$ in each well. Cell viability was determined by a 3,4,5-dimethylthiazol-2,5 biphenyl tetrazolium bromide (MTT-Life Technologies, USA) assay. The absorbance of cell viability was examined using a spectrophotometer with a microplate reader at a wavelength of $595 \mathrm{~nm}$ (Biorad; plate reader, USA).

\subsection{Data Analysis}

Experiments were performed in independent triplicates and data are presented as the mean \pm SD. Statistical analysis was performed using Graphpad Prism (version 8, San Diego California, USA). One-way ANOVA was used to compare statistical difference between control and treated groups followed by Tukey's multiple comparisons test. Significant difference was taken as $p<0.05$.

\section{Results}

\subsection{Computational Analysis of S. mutans Glucansucrase Binding Potential of Mangiferin}

Docking analysis of $S$. mutans glucansucrase and mangiferin revealed binding energy of -7.35 and 10 hydrogen interactions (Table 2). It was noticed that a hydrogen bond between ASPS'593/OD1 of glucansucrase and C7-OH of mangiferin with a bond length of $2.2 \AA$. Two hydrogen bonds were noticed between ASP'588/OD2 of glucansucrase and $\mathrm{C} 1-\mathrm{OH}$ and $\mathrm{C}^{\prime}-\mathrm{OH}$ group of mangiferin respectively with bond length of 2.0 A. Similarly, two hydrogen bonds were noticed between ASP'909/OD1 of glucansucrase and $\mathrm{C}^{\prime}-\mathrm{OH}$ and $\mathrm{C}^{\prime}-\mathrm{OH}$ group of mangiferin with bond length of $2.1 \AA$ and $2.5 \AA$ respectively. Amino acid, GLN'592/1HE2 of glucansucrase and C2'-O group of mangiferin revealed a hydrogen interaction with a bond length of $2.4 \AA$. While both the amino acids HIS'587/HE2 and ARG' $475 / 1 \mathrm{HH} 2$ of glucansucrase interacted with $\mathrm{C} 6{ }^{\prime}-\mathrm{O}$ group of mangiferin with a hydrogen bond length of $2.4 \AA$ and $2.0 \AA$ (Figure 1A,B; Table 2).

Table 2. Hydrogen bond interaction of mangiferin and amino acid residues of $S$. mutans glucansucrase.

\begin{tabular}{|c|c|c|c|c|c|c|}
\hline SL.No & Ligand & $\begin{array}{l}\text { Binding } \\
\text { Energy }\end{array}$ & $\begin{array}{l}\text { Ligand } \\
\text { Efficiency }\end{array}$ & $\begin{array}{l}\text { Intermole } \\
\text { Energy }\end{array}$ & Ligand Atoms (Ring) & $\begin{array}{c}\text { Docked Amino } \\
\text { Acid Residue (Bond Length) }\end{array}$ \\
\hline 1. & Mangiferin & -7.35 & -0.25 & -8.66 & $\begin{array}{l}\mathrm{C} 7-\mathrm{OH}(\mathrm{B}) \\
\mathrm{C} 1-\mathrm{OH}(\mathrm{A}) \\
\mathrm{C} 2^{\prime}-\mathrm{O} \\
\mathrm{C} 2^{\prime}-\mathrm{OH} \\
\mathrm{C} 3^{\prime}-\mathrm{OH} \\
\mathrm{C} 3^{\prime}-\mathrm{O} \\
\mathrm{C} 4^{\prime}-\mathrm{O} \\
\mathrm{C} 6^{\prime}-\mathrm{O} \\
\mathrm{C} 6^{\prime}-\mathrm{O} \\
\mathrm{C} 6^{\prime}-\mathrm{OH}\end{array}$ & 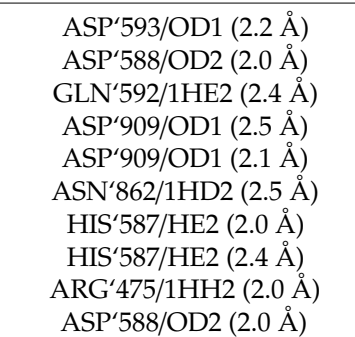 \\
\hline
\end{tabular}



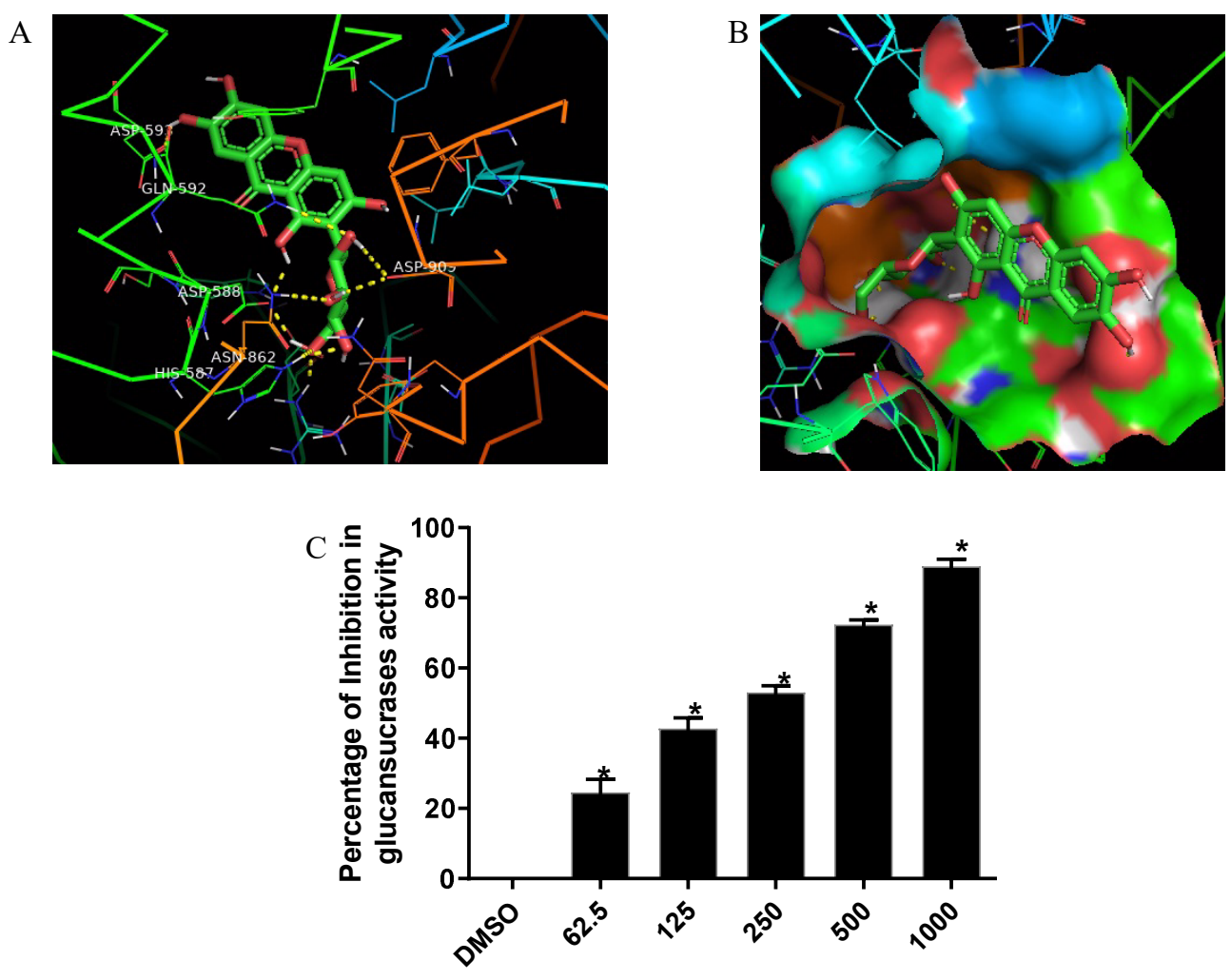

Concentration of mangiferin in $\mu \mathbf{M}$

Figure 1. (A) Docked orientation of mangiferin to S. mutans glucansucrase (PDB ID: 3AIB); (B) Glucansucrase binding pocket representation for mangiferin in glucansucrase; (C) S. mutans glucansucrase inhibitory potential of mangiferin. The values are mean of three replicates \pm standard deviations (SD). ${ }^{*} p<0.05$, represents significant difference compared with the control group.

\subsection{Mangiferin Inhibition of S. mutans Glucansucrase Activity}

The resultant outcome of computational studies motivated us to study the biological effect of mangiferin on $S$. mutans glucansucrase activity. Inclusion of mangiferin in glucansucrase reaction mixture resulted in concentration dependent inhibition in glucansucrase activity (Figure 1C). Mangiferin revealed glucansucrase inhibition starting from the lowest test concentration $(62.5 \mu \mathrm{m})$. Mangiferin at the higher concentrations of $500 \mu \mathrm{m}$ and $1000 \mu \mathrm{m}$ inhibited more than $75 \%$ of glucansucrase activity as compared with those of the DMSO control.

\subsection{Antibacterial Activity of Mangiferin against Planktonic S. mutans}

Results of the antibacterial investigation using disc diffusion assay revealed that mangiferin was not lethal to $S$. mutans in the test concentrations ranging from $62.5 \mu \mathrm{m}$ to $1000 \mu \mathrm{m}$ (Figure $2 \mathrm{~A}$ ). Compared to the DMSO control, a significant decrease was initially observed with concentrations of $250 \mu \mathrm{m}$ after $30 \mathrm{~h}$ but did not affect the overall growth curve. Even then, the growth curve assay with an extended incubation period of up to $42 \mathrm{~h}$ also indicated that mangiferin was not lethal to planktonic S. mutans culture (Figure 2B).

\subsection{Mangiferin Suppressed S. mutans Biofilm}

Similar to the inhibition of glucansucrase activity, mangiferin was also seen to have inhibited S. mutans biofilm formation in a concentration dependent manner (Figure 3). Also, biofilm inhibitory activity of mangiferin was noticed for the least test concentration of $62.5 \mu \mathrm{m}$ (Figure 3A). Although the biofilm inhibitory potential was less in lower test concentrations, this inhibitory ability by mangiferin 
was seen to have increased in concentration-dependent manner. The test concentration of $1000 \mu \mathrm{m}$ inhibited more than $90 \%$ of the S. mutans biofilm formation on plastic culture plates. Furthermore, microscopic examination of biofilm in plastic culture plate revealed concentration dependent decrease in bacterial biofilm on the surfaces (Figure 3B). Also, treatment with mangiferin treated $(62.5 \mu \mathrm{m}$ to $1000 \mu \mathrm{m}$ ) biofilm stained with acridine orange, observed under fluorescent microscope at $40 \mathrm{X}$ magnification, showed a concentration-dependent reduction (Figure 3C). This significant reduction $(p<0.05)$ of $S$. mutans biofilm formation ranged from $11 \%$ to $94 \%$, evidently indicating that mangiferin has the potential to inhibit dental plaque biofilm formation.

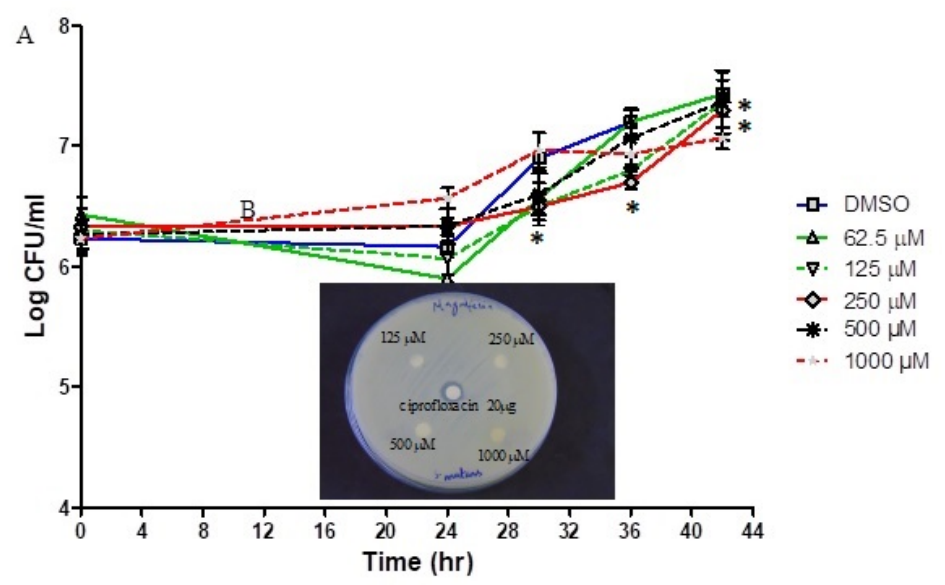

Figure 2. (A) Effect of mangiferin on growth pattern of S. mutans planktonic cell cultures using time kill assay. The concentrations of mangiferin ranged from $62.5 \mu \mathrm{m}$ to $1000 \mu \mathrm{m}$. (B) Antibacterial effect of mangiferin against $S$. mutans using disc diffusion method. The DMSO treated $S$. mutans cells grown in BHI broth was used as control. Data are means \pm standard deviation $(S D)(n=3)$. Significance difference was set at ${ }^{*} p<0.05$, from the control group.

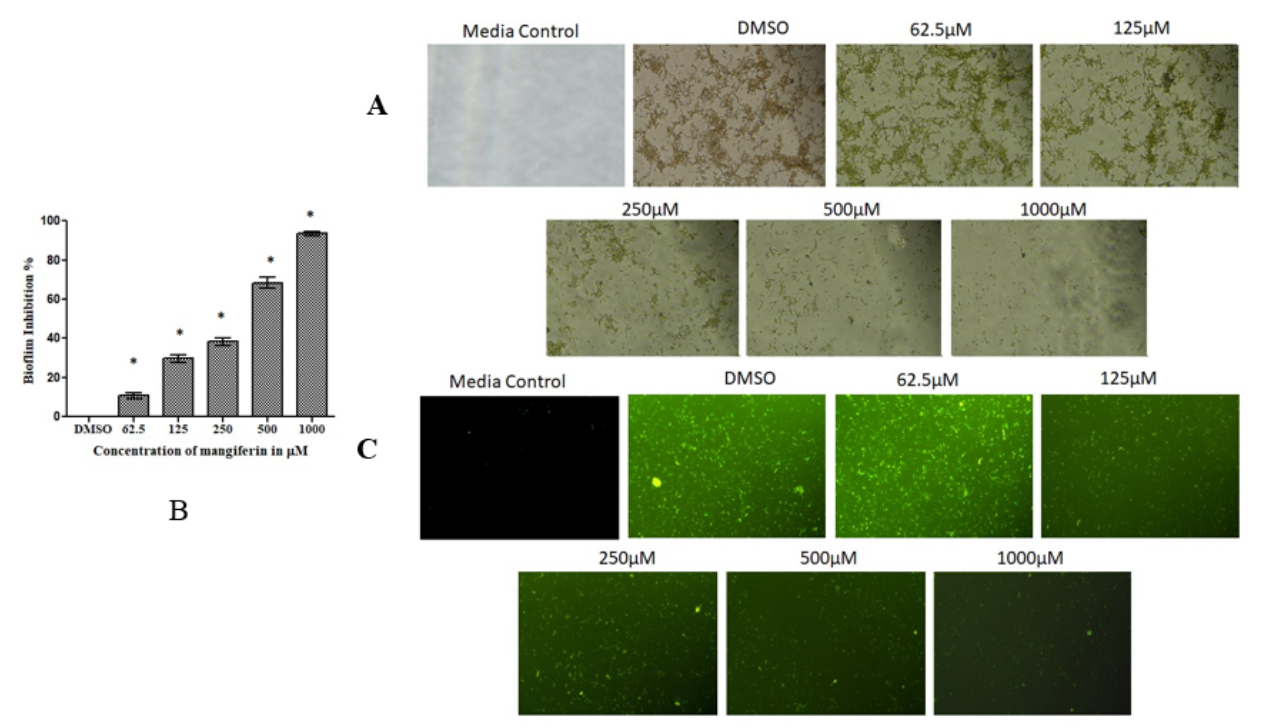

Figure 3. Mangiferin inhibitory potential against $S$. mutans biofilm formation. (A) Biofilm inhibition of mangiferin in concentrations of $62.5,125,250,500$ and $1000 \mu \mathrm{m}$ compared to DMSO control. The values are mean of three replicates $\pm \mathrm{SE} .{ }^{*} p<0.05$, represents significant difference compared with the control group. (B) Microscopic observation of $S$. mutans biofilm under the influence of mangiferin at 40× magnification; (C) Control and mangiferin treated $(62.5 \mu \mathrm{m}$ to $1000 \mu \mathrm{m})$ biofilm stained with Acridine orange observed under fluorescent microscope at $40 \times$ magnification. 


\subsection{Mangiferin Suppressed S. mutans Biofilm on Dental Surface}

On confirmation of biofilm inhibitory potential of mangiferin on plastic culture plates, we analyzed its biofilm inhibitory potential on dental surfaces. Results from our study revealed that mangiferin reduced colony-formatting units of biofilm on dental surface in a concentration dependent manner. Unlike plastic surfaces, mangiferin at low concentration $(62.5 \mu \mathrm{m})$ did not inhibited S. mutans biofilm on dental surface (Figure 4). In contrast, the biofilm formation on dental surfaces started to decrease when the tooth surfaces were treated with the concentrations ranging from $125 \mu \mathrm{m}$. Treating dental surfaces with higher concentrations of mangiferin $(500 \mu \mathrm{m}$ and $1000 \mu \mathrm{m})$ revealed more than a $75 \%$ reduction in $S$. mutans biofilm.

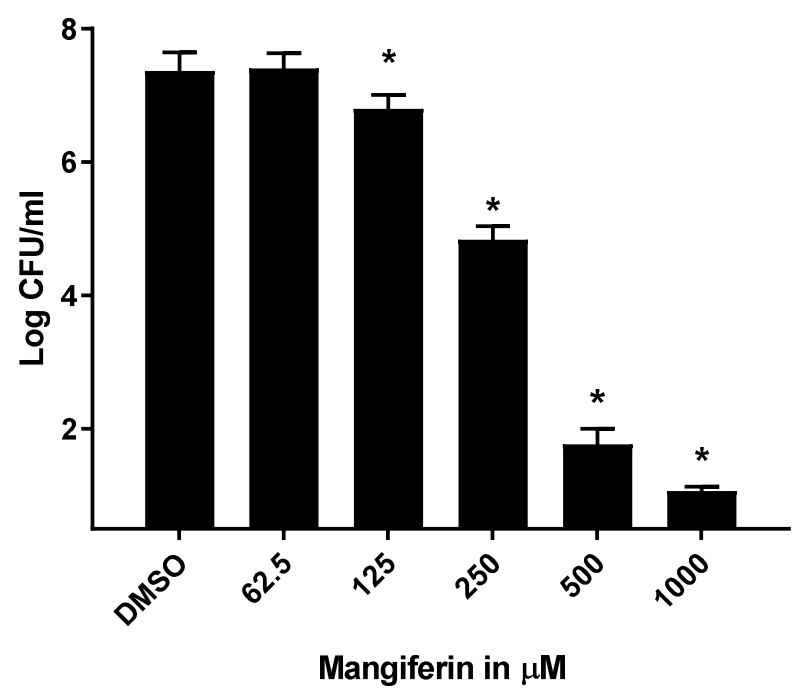

Figure 4. Effect of mangiferin on S. mutans biofilm in teeth analyzed as viable colony forming units. Data are means \pm standard deviations $(\mathrm{SD})(\mathrm{n}=3) .{ }^{*} p<0.05$ represents statistical significant difference from the control group.

\subsection{Mangiferin Inhibition of Glucan Synthesis in S. mutans Biofilm}

Similar to glucansucrase activity and biofilm formation, glucan synthesis in S. mutans was reduced by mangiferin. Mangiferin concentrations ranging from 125 to $1000 \mu \mathrm{m}$ reduced water-soluble glucan synthesis by S. mutans (Figure 5A). Similar to its effect on water-soluble glucan synthesis, mangiferin also decreased the synthesis of water insoluble glucan in concentration dependent manner (Figure 5B). Both water soluble/insoluble glucan syntheses in S. mutans biofilm were not affected when it was treated with a lower concentration of mangiferin $(62.5 \mu \mathrm{m})$.

\subsection{Mangiferin Down-Regulated the Expression of Genes Involved in Biofilm Formation}

To study the effect of mangiferin on biofilm-related gene expression, we performed quantitative real time PCR to quantify the effect on the biofilms formed by S. mutans using test concentrations of $500 \mu \mathrm{m}$ and $1000 \mu \mathrm{m}$. Among the genes examined, the expression of $g t f B$ involved in water-soluble extracellular polysaccharide synthesis was found to be down regulated by the treatment with mangiferin (500 and $1000 \mu \mathrm{m})$. Similarly, the expression of genes involved in water-soluble and insoluble glucan production $(g t f C)$ was also down regulated by mangiferin in dose dependent manner. In addition, the expression of $g t f D$, involved in synthesis of water-soluble glucan was down regulated by mangiferin treatment. In addition, mangiferin also down regulated the expression of $g b p B$ gene encoding glucan binding protein. The gene encoding ComDE, involved in an intraspecific cell-cell communication quorum sensing system in S. mutans, was also down regulated by mangiferin (Figure 6). 

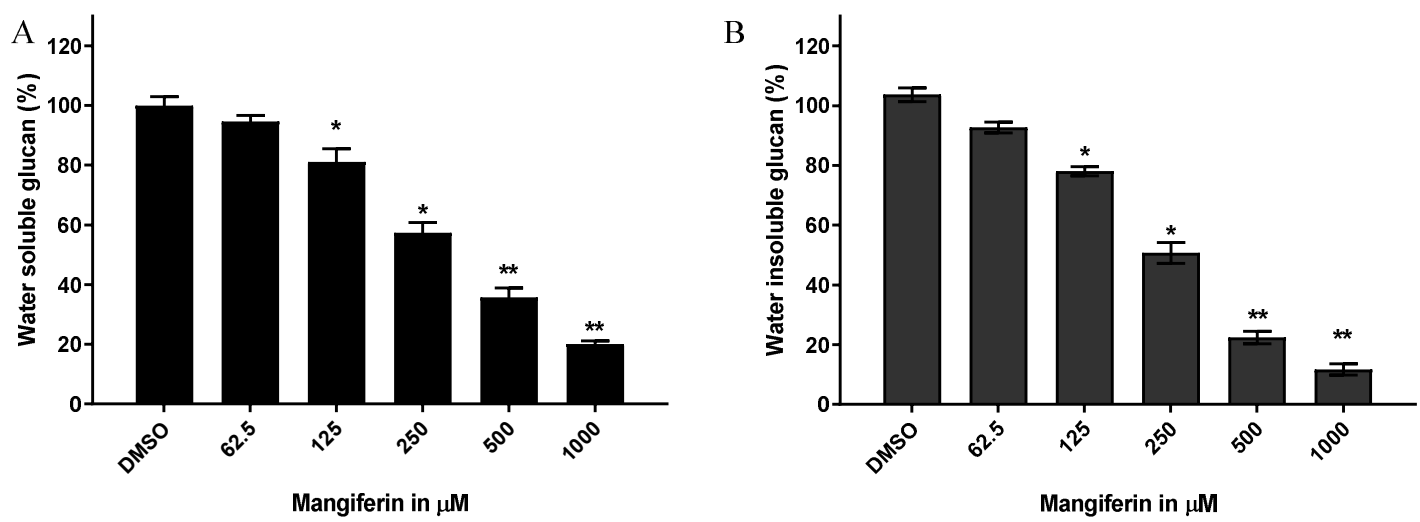

Figure 5. Effect of mangiferin on glucan synthesis in S. mutans. (A) Water soluble glucan; (B) Water insoluble glucan. Data are means \pm standard deviations (SD) $(\mathrm{n}=3)$. ${ }^{*} p<0.05$, and ${ }^{* *} p<0.001$ represent statistical significant differences from the control group.

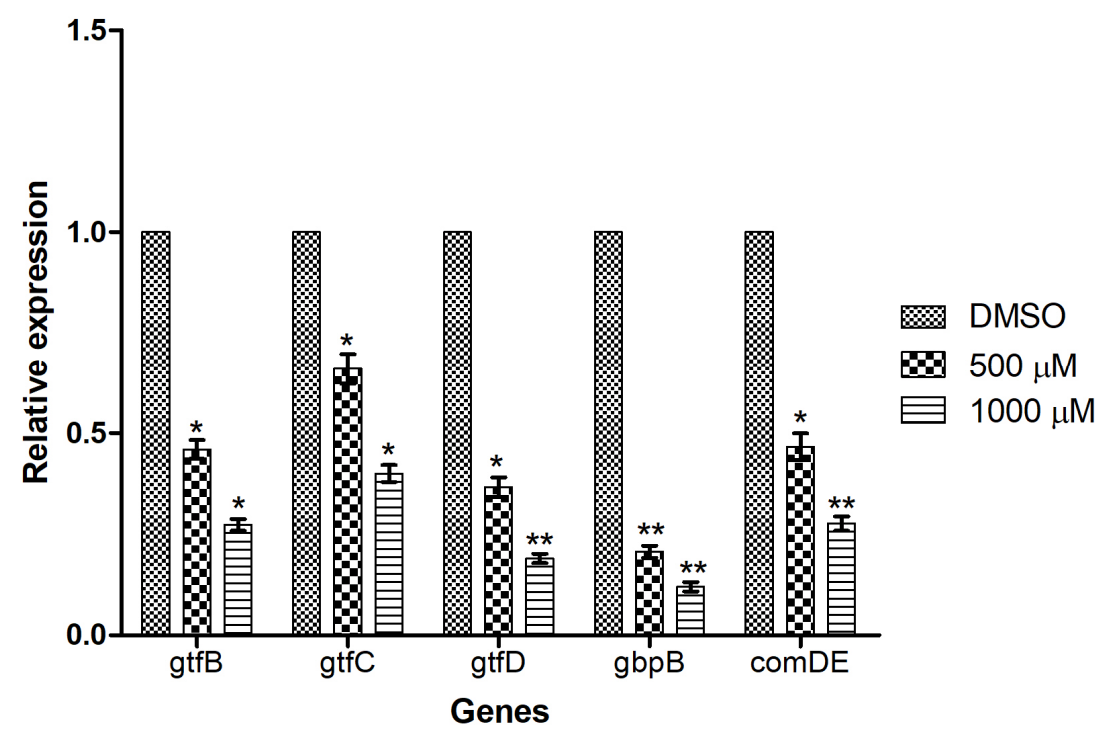

Figure 6. Effect of mangiferin on expression of genes involved in S. mutans biofilm formation. Data means \pm standard deviations $\left(\mathrm{SD}(\mathrm{n}=3) .{ }^{*} p<0.05,{ }^{* *} p<0.01\right.$, represents significantly statistical difference from the control group.

\subsection{Scanning Electron Microscopic Observation of Biofilm}

In addition to the biofilm inhibitory potential of mangiferin on plastic culture plates, we also analyzed the SEM data of control and mangiferin treated biofilms. The SEM images revealed attached of S. mutans biofilm in both the control and mangiferin treated tooth surfaces (Figure 7A,B). In contrast, mangiferin induced biofilm disruption (or inhibition) and associated microbial cell morphology was examined using scanning electron microscope of mangiferin treated tooth surface (Figure 7B). As shown in Figure 7B, the S. mutans biofilm density was scanty in mangiferin treated tooth on comparison to non-treated control tooth (Figure 7A). In addition, both the pattern of biofilm and cells distribution was also different in the control and the mangiferin treated tooth surface, showing scanty and distorted colonies. 
A

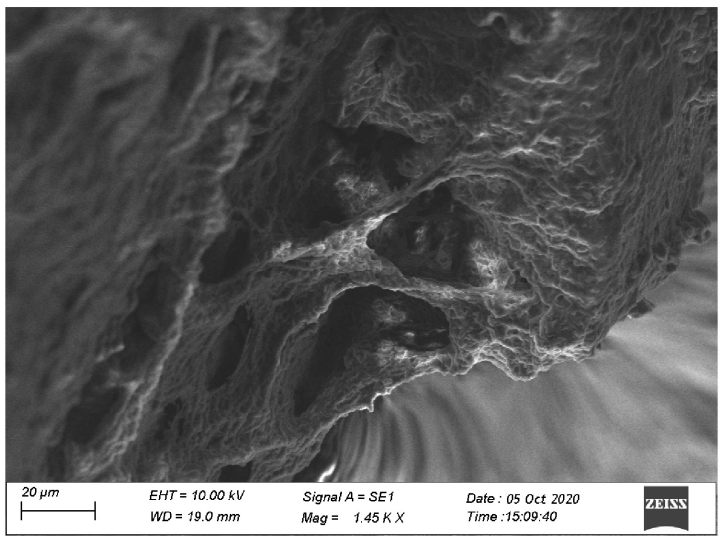

B

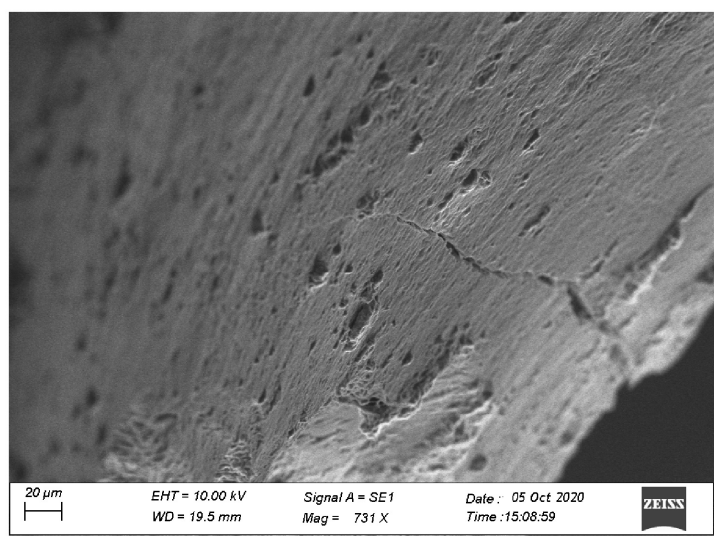

Figure 7. SEM images showing biofilm of $S$. mutans on control and mangiferin treated tooth. (A) The biofilm formation on vehicle control (DMSO) treated tooth surface; (B) Biofilm formation on mangiferin $(500 \mu \mathrm{m})$ treated tooth surface.

\subsection{Hemo Toxicity}

The hemotoxicity of mangiferin was studied by examining haemolytic activity against human red blood cells (RBCs) using Chlorhexidine $0.2 \%$ as positive control. There were no differences between $1 \%$ DMSO and mangiferin concentrations used. This indicated that mangiferin did not exhibit any toxicity on RBC. However, $0.2 \%$ chlorhexidine showed about $3-4$-fold increased haemolysis compared to mangiferin and DMSO (Figure $8 \mathrm{~A}$ ).

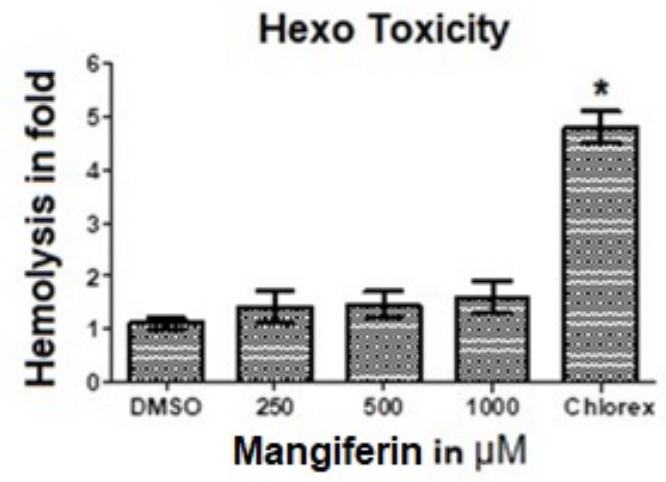

A

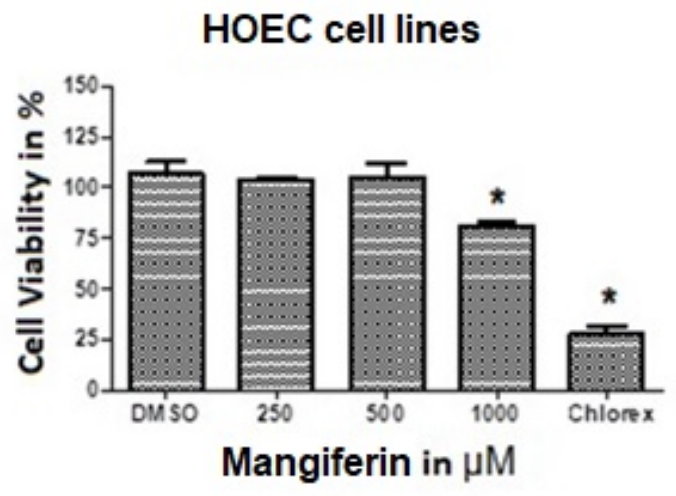

B

Figure 8. Hemolysis and Cytotoxicity of mangiferin. Hemolytic activity of mangiferin in concentrations of 250 and $500 \mu \mathrm{m}$ against human RBC cells and HOEC cells. After $24 \mathrm{~h}$ of incubation with the mangiferin, (A) Hemolytic activity of the mangiferin against red blood cells. The release of hemoglobin was measured using a microplate reader at $414 \mathrm{~nm}$. Hemolytic level was noted in fold. (B) Cytotoxicity was measured using an MTT (3-(4, 5-dimethylthiazol-2-Yl)-2, 5-diphenyltetrazolium bromide) assay. * $p<0.05$ represents significant difference between the control and. mangiferin treated groups.

\subsection{MTT Assay and Cytotoxicity Analysis}

Results of the effects of mangiferin on the cell viability of human oral epithelial cell line (HOEC) were studied as presented in Figure 8B. There were no effects on cell viability by concentrations of 250 and $500 \mu \mathrm{m}$ mangiferin. The result obtained is comparable to that observed for the negative control, $1 \%$ DMSO. However, $1000 \mu \mathrm{m}$ of mangiferin gave $75 \%$ cell viability compared to $0.2 \%$ chlorhexidine, which significantly $(p<0.05)$ decreased cell viability. This indicates that mangiferin does not suppress cell viability and potentially has no deleterious effects when applied on oral mucosa cells. 


\section{Discussion}

Biofilm production by $S$. mutans is critical in the pathogenesis of dental plague associated oral diseases $[38,39]$. Several natural products have been evaluated for their anti-plaque properties in an effort to attenuate oral bacteria biofilm formation [28,38,39]. However, most of them have shown detrimental effects on the oral microbiome. Numerous studies have shown that inhibiting glucansucrase synthesis will affect the ability of $S$. mutans to produce extracellular polysaccharide-like glucans implicated in the pathogenicity of dental plaque $[16,40]$. Glucansucrase provides the binding elements that create the enabling environment for biofilm formation. In the present study, we report the inhibitory potentials of mangiferin, a naturally synthesized product from Mangifera indica, on glucansucrase's glucan synthesis. Using a computational approach, we demonstrated a significant binding interaction of mangiferin with glucansucrase at domains $\mathrm{A}$ and $\mathrm{B}$ amino acid sequence. Documented evidence indicates that these domains harbor the enzyme's catalytic sites [41,42]. The binding interactions as revealed by docking analysis in this study occurred at 8 regions of the amino acid components of glucansucrase. Interestingly, ARG 475, ASP 588, and ASP 593, which were involved in this binding interaction, are considered as the enzyme's catalytic active sites $[43,44]$. ARG 475 was identified as a key stabilizer of the biofilm structure, whereas ASP 593 is reported by Ito et al. [43] to have a critical influence on transglycosylation. This phenomenon is responsible for the production of either soluble or insoluble glucan. Therefore, the binding interaction of mangiferin with glucansucrase provided the impetus to explore its potential to inhibit biofilm formation. Abundant evidence shows that the production of glucan by glucansucrase secreted by S. mutans is the main pathogenic feature implicated in dental biofilm formation [45]. Hence, suppressing the ability of glucansucrase to synthesize glucan will in turn reduce the generation of polysaccharide production and disrupt bacteria dental plaque formation. Ren et al. [45] reported that a glucan synthesized polysaccharide matrix enhances early phase bacteria adherence to tooth surfaces. It also acts as a crucial carbohydrate reserve, shielding the microbes from antibacterial action [46]. The present study indicates that mangiferin inhibited glucansucrase activity in a concentration-dependent manner by $75 \%$. However, the observation, that all concentrations of mangiferin did not affect the growth of planktonic S. mutans is contrary to earlier reports by Quang et al., [26] and Banavar et al., [47], who documented antibacterial activity of extracts of Mangifera indica leaves. A number of molecules of natural origins are reported to inhibit $S$. mutans activity, particularly, essential oils as documented by Le et al. [48] and Ács et al. [49]. This attribute places essential oils as a likely alternative to antimicrobials, particularly with the emergence of multi drug resistance. It could also, reduce their ability to be pathogenic [49]. Ashraf et al. [50], reported antibiofilm activity of Mentha piperita essential oils against S. mutans. The present work showed a mangiferin-induced suppressing effect on the biofilm formation in concentration-dependent fashion. This effect is consequent to the inhibition of glucansucrase as aforementioned. Colony-forming units (CFU) were reduced as well, indicating that mangiferin could be a potential candidate in the control of dental plaque formation. Our findings are in agreement with the work of Quang et al. [26]. The inability of S. mutans to form colonies in the presence of mangiferin decreased the bacteria's propensity to form biofilm in the absence of adherent glucan. This affected the ability of $S$. mutans to create an enabling microbial environment that is appropriate for colonization and subsequently plaque formation [12]. Documented evidence shows that the presence of biofilm is a risk factor for periodontitis, which generates inflammatory reactions [51]. Furthermore, the presence of periodontitis and the attendant inflammation has been associated with diseases like endothelial dysfunction and coronary heart disease [52]. Therefore, the treatment of biofilm associated dental diseases is an important health approach. Moreover, a recent report confirms the link between pathogenic oral bacteria and the progression of periodontal-induced biofilm [25]. Visualization with confocal imaging confirmed concentration-dependent dispersion and loose colonies with mangiferin treatment in this study. These findings indicate that mangiferin potentially disturbed the process of adherence in early S. mutans colonizers, thereby interrupting biofilm formation. The studies of Shafiei et al. [38] and Quang et al. [26] thus support this outcome and this could mean an anti-adherent 
property. The behavior of $S$. mutans to aggregate and adhere contributes to the pathogenesis of dental plaque. If not controlled, will eventually lead to dental caries and associated diseases of the oral cavity [10]. In addition, biofilm analysis on the tooth showed that viable CFU were significantly reduced. Meaning that microbial milieu favourable to colonization has been altered by mangiferin. Evidently, from this present study, the synthesis of water-soluble and water insoluble glucans were reduced in the presence of mangiferin. These effects were only achieved in the concentration of $125-1000 \mu \mathrm{m}$ of mangiferin. Reported studies show that $S$. mutans utilizes water soluble glucan to interact with salivary proteins in the oral cavity, whereas the synthesized water insoluble glucan is used to form stable dental plaques with increased adherence that attract other microbes $[39,53]$. Other natural products like EGCC and Ethyl gallate have similarly been reported to suppress the propensity of $S$. mutans to synthesize both water-soluble and water-insoluble glucans $[39,53]$. In our study, mangiferin suppressed biofilm formation on the tooth surface by attenuating the very element that enables adhesion. Furthermore, to evaluate the effect of mangiferin on gene expression of glucansucrase virulence elements used by $S$. mutans to form and maintain functional biofilms. The elucidation of these genes and their presence provided more information about the mode of action of mangiferin. Here, we demonstrated that mangiferin significantly downregulated the expression of $g t f B, g t f C$, and $g t f D$ virulence genes involved in biofilm formation. The inhibition compromised their ability to express their full virulence attributes. Evidence indicates that reduced expressions of these genes proactively decreased the production of extracellular polysaccharide, bacterial aggregation, and consequently biofilm formation [39]. In addition, mangiferin was found to reduce the expression of glucan binding protein $(g b p B)$. It is noted to be responsible for mediating microbial cell adhesion and plays an active role in the maturation of biofilm [54]. Our finding is consistent with the report of Ashraf et al. [50] who documented the reduction of the $g b p B$ virulent gene involved in biofilm formation using a modified natural compound. Another essential element critical for dental plaque development, used by S. mutans to establish persistent biofilm, is the competence stimulating peptide (CSP) gene comDE [55]. The comDE gene is involved in the quorum-sensing system, regulating the expressions and competence of glucanotransferase enzymes. It also modulates the oral microbial environmental adaptation of bacteria involved in biofilm formation [56]. In our present investigation, we report that mangiferin suppressed comDE gene expression. Hasan et al. [10] demonstrated that the suppression of comDE expression is critical for plaque formation, affecting cell wall integrity and the loss of adherence. Reports indicate that $S$. mutans utilizes this gene to respond to changes within the oral environment by membrane signal transduction [55]. Our results are in agreement with other studies that showed the downregulation of this gene and a consequent disruption of biofilm formation [12,57]. Moreover, SEM results analysis revealed that exposure of $S$. mutans to mangiferin on the teeth surfaces showed disruption of plaque formation with scanty biofilm density. The scanty appearance of aggregated cells in the treated teeth sample can be interpreted to mean glucan synthesis inhibition. Unlike the treated teeth, the untreated teeth appeared clustered with a sticky glucan surface. Therefore, the SEM analysis further validates both the glucan synthesis and virulence gene elements inhibitions. Finally, the overall effect of mangiferin is demonstrated by this study to be antibiofilm formation. The fact that mangiferin did not alter the growth of planktonic $S$. mutans appear to set it apart as a potential therapeutic agent. This is suggested to be an advantage in that its use will therefore not alter the oral microbiome. The use of current antibiotics in the treatment of dental plaques affects not only S. mutans but also oral bacterial flora. The safety profile of mangiferin was also evaluated on human oral epithelial cell line (HOEC) and it was demonstrated not to be cytotoxic and to have no effect on cell viability. This observation was also demonstrated on human RBC and was seen to produce no haemolysis. Our finding confirms the report of other studies that stated that mangiferin is without any side effects or toxicity [58].

\section{Conclusions}

The present study has demonstrated that mangiferin has the potential to bind S. mutans glucansucrase and inhibit its activity. Given that mangiferin did not affect planktonic S. mutans 
growth, the oral microbiome will not be altered. The study also showed that mangiferin antibiofilm activity occurs via the inhibition of the virulence gene elements of $S$. mutans. By so doing, adherence attributes are attenuated, colonization reduced, and aggregation diminished, thereby providing an apparent insight into its antibiofilm propensity. Further investigations are needed to expand the scope of mangiferin's antibiofilm potential with a view towards future clinical studies. Particularly as an anti-inflammatory agent, mangiferin has established potential to attenuate inflammatory related diseases caused by periodontal disease.

\section{Study Limitations}

In this study, we compared the effects of oral mouthwash containing the antibiotic chlorhexidine to show the safety profile of mangiferin as an antibiofilm agent. Therefore, this study has opened a new study perspective, that is, to compare mangiferin with other agents that are currently used in the treatment of dental biofilm. Therefore, the limitation was that we compared it with chlorhexidine alone.

Author Contributions: Conceptualization/design, P.M.E., L.I.B.-E., H.-I.M.I., and K.T.; methodology, P.M.E., L.I.B.-E., H.-I.M.I., K.T., and J.H.; software, H.-I.M.I. and K.T.; formal analysis, P.M.E., L.I.B.-E., H.-I.M.I., and K.T.; project administration/funding acquisition, P.M.E.; writing—original draft preparation, P.M.E., L.I.B.-E., H.-I.M.I., K.T., and J.H.; writing-review and editing, P.M.E., L.I.B.-E., H.-I.M.I., K.T., and J.H. All authors have read and agreed to the published version of the manuscript.

Funding: This research was funded by the Deputyship for Research and Innovation, Ministry of Education, Saudi Arabia via the "Support the identity of King Faisal University through institutional Financing track 2020" project number: IFT20103.

Acknowledgments: The authors extend their appreciation to The Institutional Financing Committee at King Faisal University and Deputyship for Research and Innovation, Ministry of Education, Saudi Arabia, for supporting this research work.

Conflicts of Interest: The authors declare no conflict of interest, financial or otherwise.

\section{References}

1. De Oliveira, J.S.; Pinto, M.E.; Santana, L.A.; Pinto, A.S.; Di Lenardo, D.; Vasconcelos, D.F. Biological effects of medicinal plants on induced periodontitis: A systematic review. Int. J. Dent. 2016, 3719879. [CrossRef]

2. Lin, N.J. Biofilm over teeth and restorations: What do we need to know? Dent. Mater. 2017, 33, 667-680. [CrossRef] [PubMed]

3. Mira, A.; Simon-Soro, A.; Curtis, M.A. Role of microbial communities in the pathogenesis of periodontal diseases and caries. J. Clin. Periodontol. 2017, 44, S23-S38. [CrossRef] [PubMed]

4. Global Burden of Disease (GBD) 2015. Disease and injury incidence and prevalence collaborators. Global, regional, and national incidence, prevalence, and years lived with disability for 310 diseases and injuries, 1990-2015: A systematic analysis for the Global Burden of Disease study 2015. Lancet 2016, 388, 1545-1602. [CrossRef]

5. Abdel-Aziz, M.M.; Emam, T.M.; Raafat, M.M. Hindering of cariogenic Streptococcus mutans biofilm by fatty acid array derived from an endophytic Arthrographis kalrae strain. Biomolecules 2020, 10, 811. [CrossRef]

6. Moynihan, P. Sugars and dental caries: Evidence for setting a recommended threshold for intake. Adv. Nutr. 2016, 7, 149-156. [CrossRef]

7. Zhang, C.; Kuang, X.; Zhou, Y.; Peng, X.; Guo, Q.; Yang, T.; Zhou, X.; Luo, Y.; Xu, X. A Novel small molecule, ZY354, inhibits dental caries-associated oral biofilms. Antimicrob. Agents Chemother. 2019, 63. [CrossRef]

8. Marsh, P.D. Microbiology of dental plaque biofilms and their role in oral health and caries. Dent. Clin. N. Am. 2010, 54, 441-454. [CrossRef] [PubMed]

9. Liu, S.; Chen, M.; Wang, Y.; Zhou, X.; Peng, X.; Ren, B.; Li, M.; Cheng, L. Effect of Veillonella parvula on the physiological activity of Streptococcus mutans. Arch. Oral. Biol. 2020, 109, 104578. [CrossRef]

10. Chen, L.; Ren, Z.; Zhou, X.; Zeng, J.; Zou, J.; Li, Y. Inhibition of Streptococcus mutans biofilm formation, extracellular polysaccharide production, and virulence by an oxazole derivative. Appl. Microbiol. Biotechnol. 2016, 100, 857-867. [CrossRef] [PubMed] 
11. Guo, L.; McLean, J.S.; Lux, R.; He, X.; Shi, W. The well-coordinated linkage between acidogenicity and aciduricity via insoluble glucans on the surface of Streptococcus mutans. Sci Rep. 2015, 10, 18015. [CrossRef] [PubMed]

12. Hasan, S.; Danishuddin, M.; Khan, A.U. Inhibitory effect of Zingiber officinale towards Streptococcus mutans virulence and caries development: In vitro and in vivo studies. BMC Microbiol. 2015, 15, 1. [CrossRef]

13. Krzyściak, W.; Jurczak, A.; Kościelniak, D.; Bystrowska, B.; Skalniak, A. The virulence of Streptococcus mutans and the ability to form biofilms. Eur. J. Clin. Microbiol. Infect. Dis. 2014, 33, 499-515. [CrossRef] [PubMed]

14. Kaur, G.; Balamurugan, P.; Princy, S.A. Inhibition of the Quorum Sensing System (ComDE Pathway) by Aromatic 1,3-di-m-tolylurea (DMTU): Cariostatic Effect with Fluoride in Wistar Rats. Front. Cell. Infect. Microbiol. 2017, 7, 313. [CrossRef]

15. Wang, C.; van der Mei, H.C.; Busscher, H.J.; Ren, Y. Streptococcus mutans adhesion force sensing in multi-species oral biofilms. NPJ Biofilms Microbiomes 2020, 6, 25. [CrossRef]

16. Walsh, T.; Oliveira-Neto, J.M.; Moore, D. Chlorhexidine treatment for the prevention of dental caries in children and adolescents. Cochrane database. Syst. Rev. 2015, 4, CD008457. [CrossRef]

17. Cabral, C.T.; Fernandes, M.H. In vitro comparison of chlorhexidine and povidone-iodine on the long-term proliferation and functional activity of human alveolar bone cells. Clin. Oral Investig. 2007, 11, 155-164. [CrossRef]

18. Nijampatnam, B.; Zhang, H.; Cai, X.; Michalek, S.M.; Wu, H.; Velu, S.E. Inhibition of Streptococcus mutans Biofilms by the natural stilbene piceatannol through the inhibition of glucosyltransferases. ACS Omega 2018, 3, 8378-8385. [CrossRef]

19. Telang, M.; Dhulap, S.; Mandhare, A.; Hirwani, R. Therapeutic and cosmetic applications of mangiferin: A patent review. Expert. Opin. Ther. Pat. 2013, 23, 1561-1580. [CrossRef]

20. Jangra, A.; Arora, M.K.; Kisku, A. The multifaceted role of mangiferin in health and diseases: A review. Adv. Tradit. Med. 2020. [CrossRef]

21. Carvalho, R.R.; Pellizzon, C.H.; Justulin, L., Jr.; Felisbino, S.L.; Vilegas, W.; Bruni, F.; Lopes-Ferreira, M.; Hiruma-Lima, C.A. Effect of mangiferin on the development of periodontal disease: Involvement of lipoxin A4, anti-chemotaxic action in leukocyte rolling. Chem. Biol. Interact. 2009, 179, 344-350. [PubMed]

22. Wang, R.R.; Gao, Y.D.; Ma, C.H.; Zhang, X.J.; Huang, C.G.; Huang, J.F. Mangiferin, an Anti-HIV-1 Agent Targeting Protease and Effective against Resistant Strains. Molecules 2011, 16, 4264-4277. [PubMed]

23. Nordini, W.H.W.I.; Fathilah, A.R.; Rahim, Z.H.A. Plant extracts of Psidium guajava, Mangifera sp. and Mentha sp. inhibit the growth of the population of single-species oral biofilm. Altern. Complement. Ther. 2013, 2, 102-106. [CrossRef]

24. Abdul, R.Z.H.; Shaikh, S.; Hasnor, W.I.W.N.; Wan Harun, W.H.A.; Razak, F.A. The effect of selected plant extracts on the development of single-species dental biofilms. J. Coll. Physicians Surg. Pak. 2014, 24, 796-801.

25. Isola, G.; Polizzi, A.; Patini, R.; Ferlito, S.; Alibrandi, A.; Palazzo, G. Association among serum and salivary A. actinomycetemcomitans specific immunoglobulin antibodies and periodontitis. BMC Oral Health 2020, 20, 283. [CrossRef]

26. Quang, N.V.; Dang, V.L.; Do, T.X.; Quach, M.T.; Nguyen, T.T.; Nguyen, Q.T.; Thanh, T.T.; Nguyen, T.M.P. Anticaries activity of mangiferin isolated from Mangifera indica leaves in Vietnam. Vietnam J. Chem. 2017, 55, 623-626. [CrossRef]

27. Isola, G.; Polizzi, A.; Iorio-Siciliano, V.; Alibrandi, A.; Ramaglia, L.; Leonardi, R. Effectiveness of a nutraceutical agent in the non-surgical periodontal therapy: A randomized, controlled clinical trial. Clin. Oral Investig. 2020. [CrossRef]

28. Hairul-Islam, M.I.; Arokiyaraj, S.; Kuralarasan, M.; Senthil Kumar, V.; Harikrishnan, P.; Saravanan, S.; Ashok, G.; Chellappandian, M.; Bharanidharan, R.; Muralidaran, S.; et al. Inhibitory potential of EGCG on Streptococcus mutans biofilm: A new approach to prevent Cariogenesis. 2020, 143, 104129.

29. Bai, L.; Takagi, S.; Ando, T.; Yoneyama, H.; Ito, K.; Mizugai, H.; Isogai, E. Antimicrobial activity of tea catechin against canine oral bacteria and the functional mechanisms. J. Vet. Med. Sci. 2016, 78, 1439-1445. [CrossRef]

30. Xu, X.; Zhou, X.D.; Wu, C.D. The Tea Catechin Epigallocatechin Gallate Suppresses Cariogenic Virulence Factors of Streptococcus mutans. Antimicrob. Agents Chemother. 2011, 55, 1229-1236. [CrossRef]

31. Shukla, S.; Goyal, A. 16S rRNA-based identification of a glucan-hyperproducing Weissella confusa. Enzym. Res. 2011, 1-10. [CrossRef] 
32. Kim, Y.M.; Yeon, M.J.; Choi, N.S.; Chang, Y.H.; Jung, M.Y.; Song, J.J.; Kim, J.S. Purification and characterization of a novel glucansucrase from leuconostoc lactis EG001. Microbiol. Res. 2010, 165, 384-391. [CrossRef] [PubMed]

33. Laosuwan, K.; Epasinghe, D.J.; Wu, Z.; Leung, W.K.; Green, D.W.; Jung, H.S. Comparison of biofilm formation and migration of Streptococcus mutans on tooth roots and titanium miniscrews. Clin. Exp. Dent. Res. 2018, 4, 40-47. [CrossRef] [PubMed]

34. Pandit, S.; Kim, J.E.; Jung, K.H.; Chang, K.W.; Jeon, J.G. Effect of sodium fluoride on the virulence factors and composition of Streptococcus mutans biofilms. Arch. Oral Biol. 2011, 56, 643-649. [CrossRef]

35. Koo, H.; Schobel, B.; Scott-Anne, K.; Watson, G.; Bowen, W.H.; Cury, J.A.; Rosalen, P.L.; Park, Y.K. Apigenin and $t \mathrm{t}$-Farnesol with Fluoride Effects on S. mutans Biofilms and Dental Caries. J. Dent. Res. 2005, 84, 1016-1020. [CrossRef]

36. DuBois, M.; Gilles, K.A.; Hamilton, J.K.; Rebers, P.A.; Smith, F. Colorimetric method for determination of sugars and related substances. Anal. Chem. 1956, 28, 350-356. [CrossRef]

37. Livak, K.J.; Schmittgen, T.D. Analysis of relative gene expression data using real-time quantitative PCR and the $2 \Delta \Delta C T$ method. Methods 2001, 25, 402-408. [CrossRef]

38. Shafiei, Z.; Haji, A.R.Z.; Philip, K.; Thurairajah, N. Antibacterial and anti-adherence effects of a plant extract mixture (PEM) and its individual constituent extracts (Psidium sp., Mangifera sp., and Mentha sp.) on singleand dual-species biofilms. PEERJ 2016, 4, e2519. [CrossRef]

39. He, Z.; Huang, Z.; Jiang, W.; Zhou, W. Antimicrobial Activity of Cinnamaldehyde on Streptococcus mutans Biofilms. Front Microbiol. 2019, 10, 2241. [CrossRef]

40. Lemos, J.A.; Palmer, S.R.; Zeng, L.; Wen, Z.T.; Kajfasz, J.K.; Freires, I.A.; Abranches, J.; Brady, L.J. The biology of Streptococcus mutans. Microbiol Spectr. 2019, 7, 435-448. [CrossRef]

41. Leemhuis, H.; Pijning, T.; Dobruchowska, J.M.; van Leeuwen, S.S.; Kralj, S.; Dijkstra, B.W.; Dijkhuizen, L. Glucansucrases: Three-dimensional structures, reactions, mechanism, $\alpha$-glucan analysis and their implications in biotechnology and food applications. J. Biotechnol. 2013, 163, 250-272. [CrossRef]

42. Meng, X.; Gangoiti, J.; Bai, Y.; Pijning, T.; Van Leeuwen, S.S.; Dijkhuizen, L. Structure-function relationships of family GH70 glucansucrase and 4,6- $\alpha$-glucanotransferase enzymes, and their evolutionary relationships with family GH13 enzymes. Cell. Mol. Life Sci. 2016, 73, 2681-2706. [PubMed]

43. Ito, K.; Ito, S.; Shimamura, T.; Weyand, S.; Kawarasaki, Y.; Misaka, T.; Abe, K.; Kobayashi, T.; Cameron, A.D.; Iwata, S. Crystal structure of glucansucrase from the dental caries pathogen Streptococcus mutans. J. Mol. Biol. 2011, 408, 177-186. [CrossRef] [PubMed]

44. Sánchez, L.; Mendoza, F.; Alderete, J.B.; Jiménez, V.A.; Jaña, G.A. The role of con-served arginine in the GH70 family: A computational study of the structural features and their implications on the catalytic mechanism of GTF-SI from Streptoccocus mutans. Org. Biomol. Chem. 2019, 17, 6269-6276. [CrossRef] [PubMed]

45. Ren, Z.; Chen, L.; Li, J.; Li, Y. Inhibition of Streptococcus mutans polysaccharide synthesis by molecules targeting glycosyltransferase activity. J. Oral Microbiol. 2016, 8, 31095. [CrossRef] [PubMed]

46. Koo, H.; Xiao, J.; Klein, M.I.; Jeon, J.G. Exopolysaccharides produced by Streptococcus mutans glucosyltransferases modulate the establishment of micro colonies within multispecies biofilms. J. Bacteriol. 2010, 192, 302432.

47. Banavar, R.S.; Nirupad, S.; Chippagiri, P.; Pandurangappa, R. Antibacterial Effects of Natural Herbal Extracts on Streptococcus mutans: Can They Be Potential Additives in Dentifrices? Int. J. Dent. 2017, 4921614. [CrossRef]

48. Le, N.T.; Donadu, M.G.; Ho, D.V.; Doan, T.Q.; Le, A.T.; Raal, A.; Usai, D.; Sanna, G.; Marchetti, M.; Usai, M.; et al. Biological activities of essential oil extracted from leaves of Atalantia sessiflora Guillauminin Vietnam. J. Infect. Dev. Ctries. 2020, 30, 1054-1064. [CrossRef] [PubMed]

49. Ács, K.; Balázs, V.L.; Kocsis, B.; Bencsik, T.; Böszörményi, A.; Horváth, G. Antibacterial activity evaluation of selected essential oils in liquid and vapor phase on respiratory tract pathogens. BMC Complement. Altern. Med. 2018, 27, 227. [CrossRef]

50. Ashrafi, B.; Rashidipour, M.; Marzban, A.; Soroush, S.; Azadpour, M.; Delfani, S.; Ramak, P. Mentha piperita essential oils loaded in a chitosan nanogel with inhibitory effect on biofilm formation against $S$. mutans on the dental surface. Carbohydr. Polym. 2019, 212, 142-149. [CrossRef] 
51. Isola, G.; Alibrandi, A.; Curró, M.; Matarese, M.; Ricca, S.; Matarese, G.; Ientile, R.; Kocher, T. Evaluation of salivary and serum ADMA levels in patients with periodontal and cardiovascular disease as subclinical marker of cardiovascular risk. J. Periodontol. 2020, 91, 1076-1084. [CrossRef]

52. Isola, G.; Polizzi, A.; Alibrandi, A.; Indelicato, F.; Ferlito, S. Analysis of Endothelin-1 concentrations in individuals with periodontitis. Sci. Rep. 2020, 10, 1652. [PubMed]

53. Gabe, V.; Kacergius, T.; Abu-Lafi, S.; Kalesinskas, P.; Masalha, M.; Falah, M.; Abu-Farich, B.; Melninkaitis, A.; Zeidan, M.; Rayan, A. Inhibitory effects of ethyl gallate on Streptococcus mutans biofilm formation by optical profilometry and gene expression analysis. Molecules 2019, 24, 529. [CrossRef]

54. Duque, C.; Stipp, R.N.; Wang, B.; Smith, D.J.; Höfling, J.F.; Kuramitsu, H.K. Downregulation of Gbp B, a component of the Vic RK regulon, affects biofilm formation and cell surface characteristics of Streptococcus mutans. Infect. Immun. 2011, 79, 786-796. [CrossRef] [PubMed]

55. Bedoya-Correa, C.M.; Rincón Rodríguez, R.J.; Parada-Sanchez, M.T. Genomic and phenotypic diversity of Streptococcus mutans. J. Oral Biosci. 2019, 61, 22-31. [CrossRef] [PubMed]

56. Li, J.; Wu, T.; Peng, W.; Zhu, Y. Effects of resveratrol on cariogenic virulence properties of Streptococcus mutans. BMC Microbiol. 2020, 20, 99.

57. Chakraborty, B.; Burne, R.A. Effects of Arginine on Streptococcus mutans Growth, virulence gene expression, and stress tolerance. Appl. Environ. Microbiol. 2017, 83, e00496. [CrossRef]

58. Lei, Z.C.; Hu, H.; Hu, L.; Zhao, M.; Yang, Y.; Chuai, Y.; Ni, J.; Cai, J. Mangiferin aglycone attenuates radiation-induced damage on human intestinal epithelial cells. J. Cell. Biochem. 2012, 113, 2633-2642. [CrossRef]

Publisher's Note: MDPI stays neutral with regard to jurisdictional claims in published maps and institutional affiliations. 